\title{
ChemComm
}

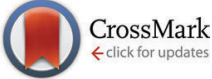

Cite this: Chem. Commun., 2015, 51, 3166

Received 19th December 2014, Accepted 14th January 2015

DOI: $10.1039 / c 4 c c 10144 h$

www.rsc.org/chemcomm

\section{Regioselective oxidative Pd-catalysed coupling of alkylboronic acids with pyridin-2-yl-substituted heterocycles $\dagger$}

\author{
Julian Wippich, Ingo Schnapperelle and Thorsten Bach*
}

\begin{abstract}
A total of 19 alkylated heterocycles (thiophenes, benzothiophenes, pyrroles, furans) were prepared (36-99\% yield) from the respective pyridin-2-yl-substituted precursors employing alkylboronic acids as the $\mathrm{C}-\mathrm{H}$ alkylating reagents in an oxidative $\left(\mathrm{Ag}_{2} \mathrm{CO}_{3}\right.$ and 2,6-dimethyl1,4-benzoquinone as oxidants) Pd-catalysed coupling reaction.
\end{abstract}

Despite considerable progress in recent years, the direct $\mathrm{C}-\mathrm{H}$ alkylation of aromatic heterocycles by transition-metal catalysis remains a considerable challenge. ${ }^{1}$ An appropriate option to achieve the desired regioselectivity in this process is based on the use of directing groups. ${ }^{2}$ In the thiophene series the pyridin-2-yl group has frequently served to mediate a reaction at position $\mathrm{C} 3$ if it was attached as a directing group to carbon atom C2. ${ }^{3,4}$ Upon $\operatorname{Pd}($ II) catalysis, oxidative dimerization of 2-pyridin-2-ylthiophene (1) proceeded selectively at $\mathrm{C}^{5}$ as did the oxidative arylation with arylboronic acids. ${ }^{6,7}$ The $\mathrm{Pd}(\mathrm{II})$ catalysed arylation of $\mathbf{1}$ with aryl bromides proceeded preferentially at C5 although the regioselectivity was variable., In this communication we disclose our results on the regioselective oxidative Pd-catalysed coupling of alkylboronic acids with 2-(pyridin-2-yl)-substituted thiophenes and related heterocycles (benzothiophene, furan, pyrrole).

The starting point of our study was a report by the Yu group, who found that 2-phenylpyridine could be alkylated with alkylboronic acids (3.0 eq.) employing a reagent combination of $\mathrm{Pd}(\mathrm{OAc})_{2}$ (10 mol\%), $\mathrm{Ag}_{2} \mathrm{O}$ (1 eq.) and 1,4-benzoquinone (0.5 eq.) at $100{ }^{\circ} \mathrm{C}$ in tert-amyl alcohol $\left({ }^{t} \mathrm{AmOH}\right) .{ }^{10,11}$ Yields varied between 51 and $75 \%$ (six examples) depending on the alkyl group. When applying the same conditions to 2-pyridin-2ylthiophene (1) and butylboronic acid we recorded a conversion of $34 \%$ after 14 hours and a product yield of $30 \%$ (determined by GLC with dodecane as internal standard). Raising the silver concentration and replacing $\mathrm{Ag}_{2} \mathrm{O}$ by $\mathrm{Ag}_{2} \mathrm{CO}_{3}$ as the silver

Department Chemie and Catalysis Research Center (CRC), Technische Universität München, 85747 Garching, Germany. E-mail: thorsten.bach@ch.tum.de;

Fax: +4989 28913315; Tel: +498928913330

$\dagger$ Electronic supplementary information (ESI) available. See DOI: 10.1039/c4cc10144h source increased the conversion to $90 \%$ and the yield to $58 \%$. Despite this significant improvement, it was notable that the butylboronic acid was largely consumed by an undesired alkylation reaction, which occurred at 1,4-benzoquinone. Indeed, it has been reported that 1,4-benzoquinone can be alkylated by alkylboronic acids under oxidative conditions in the presence of a $\operatorname{Pd}\left(\right.$ II) catalyst. ${ }^{12}$ If 1,4 -benzoquinone was omitted in the present reaction, the turnover was retarded ( $37 \%$ conversion after $14 \mathrm{~h}$ ), which confirmed the importance of 1,4-benzoquinone to complete the catalytic cycle. ${ }^{13}$ In order to find a 1,4-benzoquinone, which would be less susceptible towards alkylation, various substituted derivatives were screened (see the ESI $\dagger$ for further information). The study revealed that 2,6-dimethyl-1,4-benzoquinone (2) was a superior co-catalyst for the desired reaction as compared to unsubstituted 1,4-benzoquinone. Applying it to the otherwise unchanged reactions conditions, the yield for the desired butylated product increased according to GLC to $70 \%$ (92\% conversion). On preparative scale, the reaction delivered an almost identical result and 3-butylthiophene $\mathbf{3 a}$ was isolated in $71 \%$ yield (Table 1). Oxidative dimerisation (dehydrogenative coupling) ${ }^{14}$ to the respective $5,5^{\prime}$-dithiophene was a notable side reaction, which may at least partially account for the moderate yields, which were recorded for products $3 \mathbf{b}-3 \mathbf{e} .^{15}$ Indeed, it was shown that $5,5^{\prime}$-dithiophene $\mathbf{4}$ was formed in $60 \%$ yield from product $3 \mathbf{a}$ if the latter was subjected to oxidative coupling conditions (Scheme 1). Even in the presence of butylboronic acid, the dimer was the only product isolated. Applying exactly the reaction conditions used for the alkylation (Table 1), product 4 was obtained from $3 \mathrm{a}$ in $59 \%$ yield. A further alkylation was not observed.

When the 5-position in the thiophene was blocked the reaction outcome significantly improved (Table 2). For ethyl 2-(pyridin-2-yl)-5thiophene carboxylate, alkylation reactions proceeded cleanly and

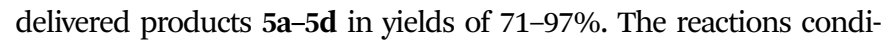
tions were compatible with ketone (product 5e) and aldehyde (product 5f) functional groups at position $\mathrm{C} 5$ of the thiophene core. Remarkably, more electron rich thiophenes also withstood the oxidative conditions of the coupling reaction. Product $5 \mathbf{g}$ was isolated in almost quantitative yield and even the 5-methoxythiophene $\mathbf{5 h}$ 
Table 1 Regioselective oxidative Pd-catalysed coupling of alkylboronic acids with 2-pyridin-2-ylthiophene $(\mathbf{1})^{a}$
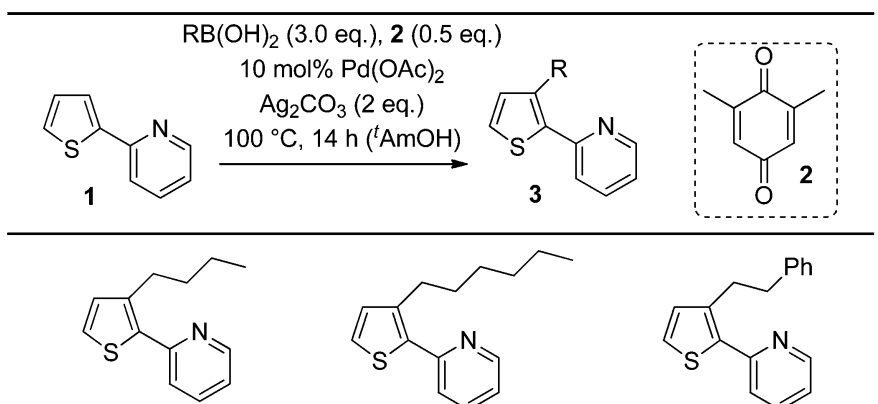

3a $(71 \%)^{b}$

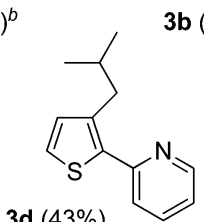

3b $(56 \%)$
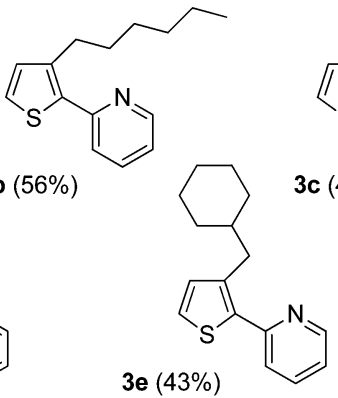

${ }^{a}$ The substrate $(c=0.2 \mathrm{M})$ and all reagents were dissolved in dry tertamyl alcohol. Upon stirring for five minutes at ambient temperature, the sealed reaction tube was placed in a pre-heated oil bath $\left(100{ }^{\circ} \mathrm{C}\right)$. Work-up was performed with $\mathrm{CH}_{2} \mathrm{Cl}_{2}$ and aqueous $\mathrm{Na}_{2} \mathrm{~S}$ solution. Yields are given for isolated products after chromatographic purification. ${ }^{b}$ GLC analysis of the crude product revealed formation of a single regioisomer.
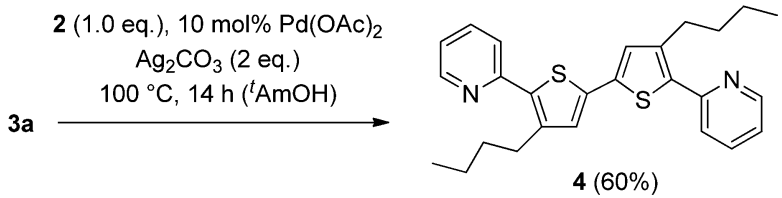

Scheme 1 Oxidative dimerisation of 3-butylated product $3 a$ to the 3,3'-dibutyl-5,5'-dithiophene 4.

could be obtained with good chemoselectivity. Moreover, it was possible to extend the reaction to 2-pyridin-2-ylbenzothiophene resulting in the alkylation products $5 \mathbf{i}$ and $\mathbf{5 j}$. Commercially available boronic acids were used in all experiments and it was secured by NMR that no condensation to the corresponding boroxines had occurred upon storage. In the course of the reaction the initially green suspension turned black possibly due to metal precipitation.

Mechanistically, it is assumed that the reaction follows the pathway previously proposed for the alkylation of benzenes. ${ }^{10}$ A mechanistic scheme is given in Scheme 2 for the transformation $1 \rightarrow$ 3a. In the event, $\mathrm{Pd}(\mathrm{OAc})_{2}$ attacks - upon precoordination to the pyridin-2-yl directing group - the thiophene core at position C3 leading to cyclopalladated intermediate 6 . Transmetallation generates the precursor 7 for the reductive elimination step, in which a reduced palladium species $\left(\mathrm{Pd}^{0}\right)$ is formed. Reoxidation to the reactive $\mathrm{PdX}_{2}$ catalyst occurs stoichiometrically by the silver salt with possible assistance by benzoquinone 2. As pointed out earlier, benzoquinone may also be involved as ligand in the transmetallation and reductive elimination step. ${ }^{12,16}$ In addition, it appears as if the 2-pyridin-2-yl group facilitates transmetalation. After primary alkylation at C3, palladation occurs at position C5 and oxidative dimerisation prevails over oxidative coupling (vide supra).
Table 2 Regioselective oxidative Pd-catalysed coupling of alkylboronic acids with 2-pyridin-2-yl-substituted thiophene and with 2-pyridin-2ylbenzothiophene ${ }^{a}$
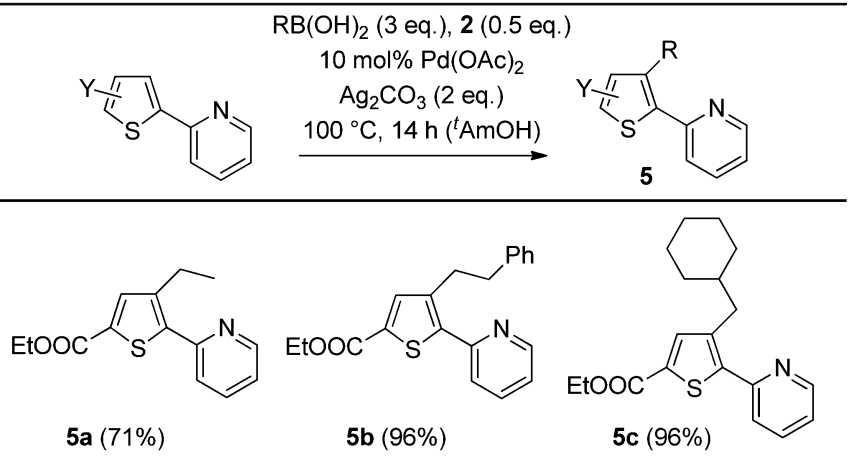<smiles>CCCCc1cc(C(=O)OCC)sc1-c1ccccn1</smiles><smiles>CCCCc1cc(C=O)sc1-c1ccccn1</smiles>

$5 f(72 \%)$

$5 \mathbf{g}(99 \%)$

5h $(66 \%)$

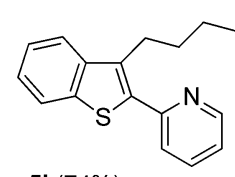

$5 \mathbf{i}(74 \%)$

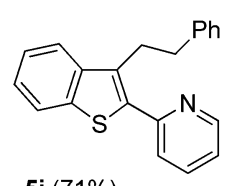

5j $(71 \%)$
${ }^{a}$ The substrate and all reagents were dissolved in dry tert-amyl alcohol. Upon stirring for five minutes at ambient temperature, the sealed reaction tube was placed in a pre-heated oil bath $\left(100{ }^{\circ} \mathrm{C}\right)$. Work-up was performed with $\mathrm{CH}_{2} \mathrm{Cl}_{2}$ and aqueous $\mathrm{Na}_{2} \mathrm{~S}$ solution. Yields are given for isolated products after chromatographic purification.

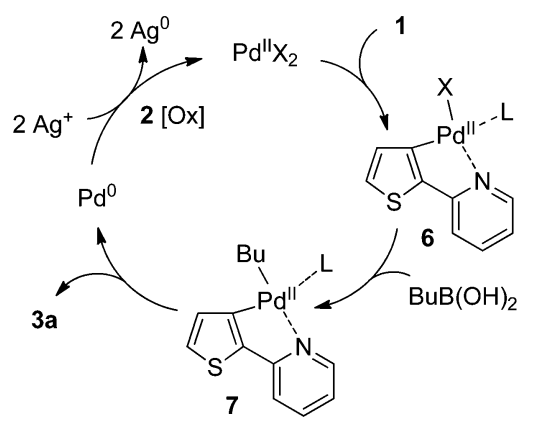

Scheme 2 Mechanistic proposal for the oxidative cross-coupling with 2-pyridin-2-ylthiophenes such as 1 ( $X=$ anionic ligand, $L=$ neutral ligand).

Given the strong directing power of the 2-pyridin-2-yl group it was probed whether a selective alkylation was also possible at other positions of the thiophene ring and with other 2-(pyridin2-yl)-substituted heterocycles as substrates. Butylboronic acid was used in these reactions as the nucleophile (Scheme 3). Gratifyingly, it was found that alkylation at position $\mathrm{C} 4^{17}$ of 3-pyridin-2-ylthiophene $\mathbf{8}$ was indeed possible employing the 

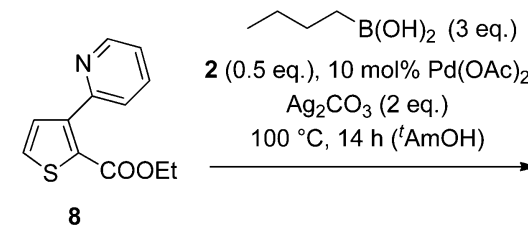

2 (0.5 eq.), $10 \mathrm{~mol} \% \mathrm{Pd}(\mathrm{OAc})_{2}$ $\mathrm{Ag}_{2} \mathrm{CO}_{3}$ (2 eq.) $100{ }^{\circ} \mathrm{C}, 14 \mathrm{~h}\left({ }^{t} \mathrm{AmOH}\right)$

8

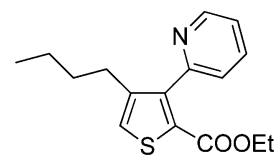

$9(52 \%)$
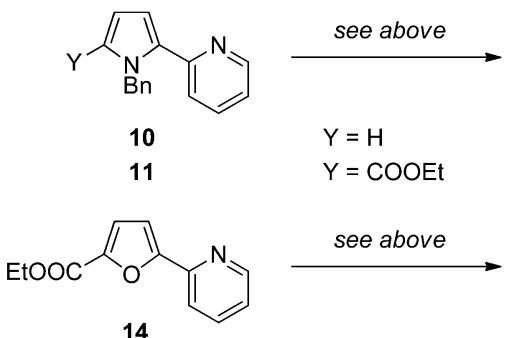

$\stackrel{\text { see above }}{\longrightarrow}$

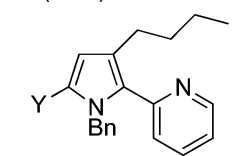

$12(58 \%)$

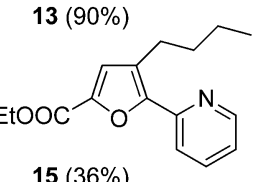

Scheme 3 Regioselective oxidative Pd-catalysed coupling of butylboronic acids with pyridin-2-yl-substituted heterocycles.

conditions previously established. Product 9 was obtained in moderate yield. In the pyrrole series, it was observed that - in analogy to product formation $\mathbf{3 a} v s$. $\mathbf{5 d}$ - the alkylation reaction of the 5-ethoxycarbonyl-substituted pyrrole $\mathbf{1 1}$ (Y= COOEt) gave a better yield than the reaction of the unsubstituted compound $10(\mathrm{Y}=\mathrm{H})$. Products yields for $\mathbf{1 2}$ and $\mathbf{1 3}$ were recorded as 58\% and $90 \%$. In the former case, competitive oxidative dimerisation at position C5 is likely the reason for the lower yields. Regarding the nitrogen protecting group, the benzyl group was shown to be superior as compared to methanesulfonyl (Ms), toluenesulfonyl (Ts) and para-methoxybenzyl (PMB). The respective 2-pyridin-2-ylpyrroles gave lower yields in the oxidative coupling reactions. The oxidation sensitive 2-pyridin-2-ylfuran gave only traces of coupling product under the standard reaction condition. The less electron rich ethyl 5-furan carboxylate 14, however, could be converted into the respective alkylation product $\mathbf{1 5}$ albeit in relatively low yield.

In summary, it was shown that the pyridin-2-yl group exerts a powerful directing influence on the Pd-catalysed $\mathrm{C}-\mathrm{H}$ alkylation of five-membered heterocycles with alkylboronic acids. The alkylation reactions occur exclusively in ortho-position to the directing group resulting in the formation of the respective 3-substituted (pyridin-2yl at C2) or 4-substituted (pyridin-2-yl at C3) products. 2,6-Dimethyl1,4-benzoquinone (2) was found to be a superior co-reagent to promote in combination with $\mathrm{Ag}_{2} \mathrm{CO}_{3}$ the oxidative coupling. If the ortho-positions relative to the directing group are substitued, oxidative dimerisation occurs under the oxidative reaction conditions at position C5 of 3-alkyl-2-(pyridin-2-yl)thiophenes.

This project was supported by the Deutsche Forschungsgemeinschaft (Ba 1372-19/1), by the Elitenetzwerk Bayern (scholarship to J.W.), by the graduate college NanoCat (scholarship to I.S.) and by the TUM Graduate School. Helmut Krause and Burghard Cordes are acknowledged for help with the HRMS analyses.

\section{Notes and references}

1 For a recent review, see: L. Jean-Gérard, R. Jazzar and O. Baudoin, in Metal-Catalyzed Cross-Coupling Reactions and More, ed. A. de Meijere, S. Bräse and M. Oestreich, Wiley-VCH, Weinheim, 2014, pp. 1427-1493.

2 Reviews: (a) M. Zhang, Y. Zhang, X. Jie, H. Zhao, G. Li and W. Su, Org. Chem. Front., 2014, 1, 843-895; (b) R. Giri, S. Thapa and A. Kafle, Adv. Synth. Catal., 2014, 356, 1395-1411; (c) K. M. Engle, T.-S. Mei, M. Wasa and J.-Q. Yu, Acc. Chem. Res., 2012, 45, 788-802; (d) T. W. Lyons and M. S. Sanford, Chem. Rev., 2010, 110, 1147-1169.

3 For alkylation reactions, see: (a) J. Kwak, Y. Ohk, Y. Jung and S. Chang, J. Am. Chem. Soc., 2012, 134, 17778-17788; (b) X. Li, S. Yu, F. Wang, B. Wan and X. Yu, Angew. Chem., Int. Ed., 2013, 52, 2577-2588; (c) X. Yu, S. Yu, J. Xiao, B. Wan and X. Li, J. Org. Chem., 2013, 78, 5444-5452; (d) S. Yu and X. Li, Org. Lett., 2014, 16, 1200-1203; (e) K. Gao, R. Paira and N. Yoshikai, Adv. Synth. Catal., 2014, 356, 1486-1490; $(f)$ K. Gao, T. Yamakawa and N. Yoshikai, Synthesis, 2014, 2024-2039.

4 For recent work on directed $\mathrm{C}-\mathrm{H}$ activation reactions at 2-pyridin2-ylthiophene, excluding $\operatorname{Pd}(\mathrm{II})$ catalysis: (a) J. Pospech, A. Tlili, A. Spannenberg, H. Neumann and M. Beller, Chem. - Eur. J., 2014, 20, 3135-3141; (b) K. Parthasarathy, A. R. Azcargorta, Y. Cheng and C. Bolm, Org. Lett., 2014, 16, 2538-2541; (c) F. Xie, Z. Qi, S. Yu and X. Li, J. Am. Chem. Soc., 2014, 136, 4780-4787; (d) X. Zhang, F. Wang, Z. Qi, S. Yu and X. Li, Org. Lett., 2014, 16, 1586-1589; (e) S. Yu and X. Li, Org. Lett., 2014, 16, 1220-1223; $(f)$ B. Zhou, H. Chen and C. Wang, J. Am. Chem. Soc., 2013, 135, 1264-1267; $(g)$ Y. Ano, M. Tobisu and N. Chatani, Synlett, 2012, 2763-2767.

5 K. L. Hull, E. L. Lanni and M. S. Sanford, J. Am. Chem. Soc., 2006, 128, 14047-14049.

6 S. Kirchberg, T. Vogler and A. Studer, Synlett, 2008, 2841-2845.

7 For a recent report on the C5-selective arylation at substrate 1, see: R. Srinivasan, R. S. Kumaran and N. S. Nagarajan, RSC Adv., 2014, 4, 47697-47700.

8 J. Laroche, K. Beydoun, V. Guerchais and H. Doucet, Catal. Sci. Technol., 2013, 3, 2072-2080.

9 For further arylation reactions on heterocycles by $\mathrm{C}-\mathrm{H}$ activation, see: (a) J. Roger, F. Požgan and H. Doucet, Green Chem., 2009, 11, 425-432; (b) S. Ranjit and X. Liu, Chem. - Eur. J., 2011, 17, 1105-1108; (c) F. Yang, Z. Xu, Z. Wang, Z. Yu and R. Wang, Chem. - Eur. J., 2011, 17, 6321-6325; (d) C. B. Bheeter, J. K. Bera and H. Doucet, J. Org. Chem., 2011, 76, 6407-6413; (e) A. M. Sajith and A. Muralidharan, Tetrahedron Lett., 2012, 53, 1036-1041.

10 X. Chen, C. E. Goodhue and J.-Q. Yu, J. Am. Chem. Soc., 2006, 128, 12634-12635.

11 For a related protocol, employing alkyltrifluoroborates as alkylating agents, see: S. R. Neufeldt, C. K. Seigermann and M. S. Sanford, Org. Lett., 2013, 15, 2302-2305.

12 Y. Fujiwara, V. Domingo, I. B. Seiple, R. Gianatassio, M. D. Bel and P. S. Baran, J. Am. Chem. Soc., 2011, 133, 3292-3295.

13 X. Chen, J.-J. Li, X.-S. Hao, C. E. Goodhue and J.-Q. Yu, J. Am. Chem. Soc., 2006, 128, 78-79.

14 Reviews: (a) C. S. Yeung and V. M. Dong, Chem. Rev., 2011, 111, 1215-1292; (b) C. Liu, H. Zhang, W. Shi and A. Lei, Chem. Rev., 2011, 111, 1780-1824; (c) J. A. Ashenhurst, Chem. Soc. Rev., 2010, 39, $540-548$.

15 The use of cyclopropyl boronic acid led to an inseparable mixture of product and substrate ( $35 \%$ conversion after $14 \mathrm{~h})$.

16 (a) K. L. Hull and M. S. Sanford, J. Am. Chem. Soc., 2009, 131, 9651-9653; (b) C. Sköld, J. Kleimark, A. Trejos, L. R. Odell, S. O. N. Lill, P.-O. Norrby and M. Larhed, Chem. - Eur. J., 2012, 18, 4714-4722.

17 For the C4-selective oxidative coupling of thiophenes with aryl boronic acids, see: (a) S. Kirchberg, S. Tani, K. Ueda, J. Yamaguchi, A. Studer and K. Itami, Angew. Chem., Int. Ed., 2011, 50, 2387-2391; (b) I. Schnapperelle, S. Breitenlechner and T. Bach, Org. Lett., 2011, 13, 3640-3643; (c) K. Yamaguchi, J. Yamaguchi, A. Studer and K. Itami, Chem. Sci., 2012, 2, 2165-2169; (d) I. Schnapperelle and T. Bach, ChemCatChem, 2013, 5, 3232-3236; (e) I. Schnapperelle and T. Bach, Chem. - Eur. J., 2014, 20, $9725-9732$. 